\title{
Erratum to: Development of Environmental Load-Estimating Model for Road Planning Phase: Focus on Road Earthwork
}

\author{
Jin-Young Park*, Dong-Eun Lee**, and Byung-Soo Kim*** \\ Received January 6, 2017/Accepted March 13, 2017/Published Online May 10, 2017
}

Erratum to: KSCE Journal of Civil Engineering (2018) 22(2):459-446

DOI 10.1007/s12205-017-0029-8

This erratum is published to notice a spelling error in keywords.

Errata:

The original version of the article was

Keywords: nvironmental load, planning phase, LCA, CBR, estimating model

Was altered as:

Keywords: Environmental load, planning phase, LCA, CBR, estimating model

The original article has been corrected.

*Member, Ph.D. Student, Dept. of Civil Engineering, Kyungpook National University, Daegu 41566, Korea (E-mail: jypark@gpc.ac.kr)

**Member, Associate Professor, Dept. of Architectural Engineering, Kyungpook National University, Daegu 41566, Korea (E-mail: dolee@knu.ac.kr)

***Member, Professor, Dept. of Civil Engineering, Kyungpook National University, Daegu 41566, Korea (Corresponding Author, E-mail: bskim65@knu.ac.kr) 